\title{
A METHOD FOR MICRO-INJECTION
}

\author{
EMILY RAY GREGORY \\ Zoological Laboratory, University of Pennsylvania \\ ONE FIGURE
}

After spending several months in an effort to secure satisfactory results and economy, of material with methods used by other workers, the writer devised the following apparatus which is very easily arranged and does the work without waste except for accidents due to inexperience or carelessness in handling.

Direct pressure is secured from a good (50c.) De Vilbiss atomizer bulb. The bulb lies on the floor and is kept from rolling by a crocheted net cover. The pressure is transmitted by a red rubber tube $\frac{3}{16}$ of an inch in diameter. After the transmitter reaches the table a short glass tube $(h)$ is inserted in it and a cord (g) run from this to the upright of a small stand with a heavy base to keep these parts in position. Eleven inches further on a glass T (r) is inserted, to the stem of which a thistle tube is joined by a short piece of rubber tubing (p). Eighteen inches more of the transmitter end with a short glass injection tube (c) which has the outer end drawn into a capillary tip at right angles to itself. A sliding rod (i) passed through the pivoted top (b) of the upright of the stand makes a convenient support for the end of the transmitter. A piece of cork (a) on the pointed bent tip of the rod gives enough friction to keep the tube from slipping and still allows it to be readily moved in either direction or removed for use, with one hand. A low Stender dish (d) for the injection fluid and a tumbler of water (b) for cleansing and protecting the injection tube are placed near the stand. A small bull-dog clip completes the essential outfit. This clip placed below the $T$ tube allows the injection tube (c) to be more quickly filled through the capillary tip by applying suction with the mouth through the thistle tube. It is then placed at $(p)$ between the $T$ and the thistle tube when pressure for injection is to be applied.

It will be noticed that this apparatus allows of modifications to suit the worker or to adapt it to special conditions. It does not seem necessary to describe dissecting stands or microscopes but a few words as to the handling of the apparatus and the preparation of certain objects may save time, temper and material for persons attempting injection for the first time.

In regard to the apparatus:

1. It is desirable to have a number of injection tubes ready for use. The writer has found it casiest to make these over a fish-tail burner, or a minim burner. Sufficient thin tubing for two tubes is heated at the centre for the shortest possible distance and when sufficiently soft, bent and quickly drawn apart. When one has secured a good tip, it is well to heat the other end enough to smooth it so that it will not cut the rubber tubing on insertion. 
2. Remember that capillary tubes are very easily broken. When not in use the injection tube should hang freely in the tumbler where it will be safe from accidents.

3 . The tip of the injection tube is very easily clogged. An injection fluid from which there may be any deposit should not be left in the tube a long time. Higgin's waterproof ink will also stand strong dilution with ammoniated water, four drops to the ounce according to their directions. If elogging occurs with the ink, egg albumen or shreds of tissue, to let the tip soak in a strong solution of $\mathrm{NaOH}$ of ten makes it possible to clear it and the $\mathrm{NaOH}$ may be easily washed out with water.

4. The clip should be removed when the apparatus is not in use.

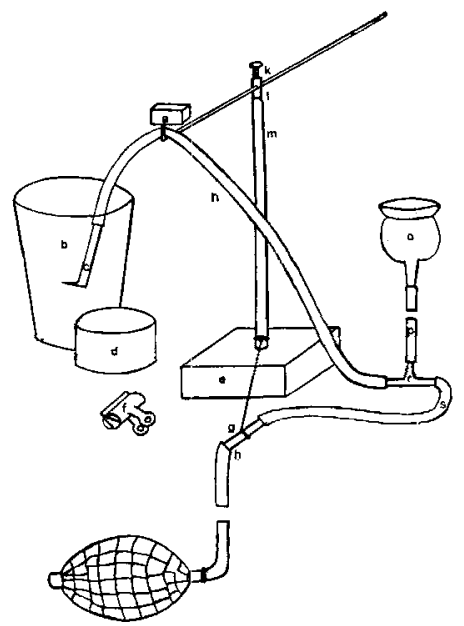

To prepare small chick or similar embryos:

Keep the egg in the position in which it is found at the time of use. Remove as much of the albumen as possible by making a small opening on the lower surface and another on the top. The lower opening must be closed as soon as the yolk membrane appears. A piece of paper held in place by one finger will answer. The upper half of the shell may then be removed and the embryo exposed. Irrigation with a warm normal salt solution helps to remove the albumen and so to prevent the clogging of the capillary tube. It is also very desirable to remove the vitelline membrane over the embryonic area if possible. The shell containing the embryo thus prepared, can easily be steadied in a low glass dish with a low raised ring near the centre. Such may sometimes be found at the ten cent stores. A brass curtain ring in a smooth dish would answer the same purpose.

Although the apparatus and method are so simple, it is desirable for any one who has never done this kind of work to practise with inexpensive material in order to gain some facility, before trying to handle that which is rare or costly. 